\title{
CONTRIBUIÇÕES DO GRUPO DE PESQUISA "LUCE - LUDICIDADE, CULTURA E EDUCAÇÃO” PARA A PRODUÇÃO DO CONHECIMENTO SOBRE O LAZER
}

Recebido em: 05/12/2017

Aceito em: 05/09/2018

\author{
Juliara Lopes da Fonseca ${ }^{1}$ \\ Instituto Federal do Norte de Minas Gerais \\ Universidade Federal de Minas Gerais \\ Belo Horizonte - MG - Brasil \\ Eduardo Penna de Sá2 \\ Universidade Federal de Minas Gerais \\ Belo Horizonte $-\mathrm{MG}-$ Brasil
}

RESUMO: O lazer é um campo de estudo interdisciplinar, atributo que amplifica e potencializa os debates sobre esse tema. A construção do saber acadêmico encontra nas Instituições de Ensino Superior um berçário para novas ideias e pontos de vista, sistematizados através dos temas estudados por grupos de pesquisa. Este artigo apresenta um mapeamento da produção de conhecimento realizada pelo grupo de pesquisa Ludicidade, Cultura e Educação - LUCE/UFMG. A metodologia escolhida foi tipo descritiva, utilizando instrumentos quanti-qualitativos, a fim de identificar e mensurar as principais temáticas de interesse nas produções do grupo, dentro do quadriênio 2014-2017. Os resultados apresentam as principais características e contribuições do grupo, que traz a ludicidade como peça-chave em suas publicações, ampliando as discussões sobre o lazer em vários territórios, especialmente no contexto latino-americano.

PALAVRAS CHAVE: Atividades de Lazer. Grupo de Pesquisa. Produção do Conhecimento.

\section{THE CONTRIBUTIONS FROM THE "LUCE - LUDICITY, CULTURE AND EDUCATION" RESEARCH GROUP FOR LEISURE KNOWLEDGE PRODUCTION}

\footnotetext{
${ }^{1}$ Mestre em Administração pela Universidade Federal de Santa Maria. Professora do Instituto Federal do Norte de Minas Gerais (IFNMG) e Bolsista PBQS-IFNMG. Doutoranda do Programa de Pós-Graduação Interdisciplinar em Estudos do Lazer da EEFFTO/UFMG. Membro do Grupo de Pesquisa Ludicidade Cultura e Educação - LUCE - EEFFTO/UFMG.

${ }^{2}$ Mestre em Administração pela Universidade Federal de Minas Gerais. Doutorando do Programa de PósGraduação Interdisciplinar em Estudos do Lazer da EEFFTO/UFMG. Membro do Grupo de Pesquisa Ludicidade Cultura e Educação - LUCE - EEFFTO/UFMG. Membro do Núcleo Interdisciplinar sobre gestão em organizações (não) empresariais - Nig.one - CEPEAD/FACE/UFMG.
} 
ABSTRACT: Leisure is an interdisciplinary field of study, attribute that helps amplifying and potentiating the discussion about this theme. The construction of academic knowledge finds in the Universities a source for new ideas and points of view, according to the themes studied by research groups. This study presents a knowledge production mapping conducted by the research group Ludicity, Culture and Education LUCE / UFMG. The methodology chosen for the study was descriptive, using quantitative-qualitative instruments, in order to identify and measure, based on textual analysis, the main themes of interest in the group's productions, within the four-year period 2014-2017. The results show the main contributions and characteristics given by the group, bringing the ludicity as important subject in its publications, reinforcing the leisure studies area in Brazil and Latin America.

KEYWORDS: Leisure Activities. Research Group. knowledge Production.

\section{Introdução: Situando o Lazer como Objeto de Estudos}

O lazer é um campo de estudo interdisciplinar, o que possibilita uma diversidade de olhares e entendimentos sobre o assunto. Uma característica que por um lado é positiva, ao permitir uma amplitude de discussões inerentes às ciências sociais e humanas, mas que por outro lado dificulta a adoção de uma concepção única capaz de refletir esse fenômeno em sua totalidade. A investigação multidisciplinar só tem a ajudar os avanços da pesquisa no tema, ao promover discussões teóricas diferenciadas, bem como a construção de novas ideias e novos enfoques. Isayama e Sousa (2006) ressaltam que a consideração de diversos pontos de vista nas reflexões sobre o lazer irão possibilitar o enriquecimento de visões críticas e novas perspectivas de construção, contribuindo para o debate e seu aprofundamento em relação ao tema.

Em se tratando das discussões pioneiras sobre o lazer, Gomes (2011) destaca que a geopolítica do conhecimento acerca desse assunto parte, em geral, de uma perspectiva eurocêntrica. Nesse âmbito, a Europa ocupa uma posição de destaque - seja para apresentar o lazer como um fenômeno moderno, advindo da urbanização e da industrialização que foram concretizadas na Inglaterra no século XIX, seja para 
considerá-lo como um fenômeno da antiguidade greco-romana. Essas duas abordagens contrapõem lazer e trabalho numa relação dicotômica e podem ser identificadas na maior parte das publicações sobre o assunto, sobretudo nos estudos pioneiros sobre a temática.

Como exemplo, pode ser citado o manifesto "O direito à preguiça”, de Paul Lafargue, uma das primeiras obras conhecidas sobre o assunto. Ao refutar o "direito ao trabalho" em um contexto de exploração da mão de obra em um regime de trabalho quase que servil, Lafargue aponta para a necessidade de uma luta de classes "não mais pelo direito ao trabalho, e sim pela distribuição social da riqueza e pelo direito de fruir de todos os seus bens e prazeres" (LAFARGUE, 1999, p.56).

Posteriormente, diversos autores como Bertrand Russel e Huizinga, nos anos 30; Riesman, nos anos 50; Friedmann, nos anos 60; Adorno e Horkheimer, nos anos 80; Lefebvre, nos anos 90; entre outros estudiosos, trouxeram contribuições aos estudos do lazer ao tratar das relações de trabalho e do lazer, a fragmentação do trabalho como forma de alienação, o lúdico e a cultura, o uso da indústria cultural para a dominação das massas e outros assuntos. Contudo, conforme destaca Marcellino (2010, p.20) é Joffre Dumazedier (1973) "o autor que mais influenciou os estudos do lazer no Brasil”, ao propor uma sociologia do lazer.

É na segunda metade do século XX que o lazer passa a ser discutido com maior ênfase no Brasil. De acordo com Gomes (2003) há um consenso entre os estudiosos da área de que as primeiras obras sobre o tema no Brasil datam do final da década de 1950 , tendo se tornado mais relevante após 1970. O contexto brasileiro no início do século XX ainda era o de uma sociedade rural, onde as relações de poder eram ditadas em função do direito sobre a terra. Com o advento das cidades a dinâmica social foi 
alterada. Com altas jornadas de trabalho, o tempo livre não era um problema, pois sua destinação era óbvia: reposição das energias para o dia seguinte de trabalho (MEDEIROS, 1971).

A partir das lutas sindicais houve a redução da jornada das horas destinadas ao trabalho e um aumento no número de dias de descanso. Consequentemente, houve o aumento do tempo livre para o lazer. Dentro desse contexto, Ferreira (1959) começou a visualizar o problema do lazer no Brasil: a existência de um tempo livre que precisava ser ocupado.

Mas antes disso, já se discutia no país algumas experiências voltadas para a recreação dos indivíduos. Essas práticas foram incentivadas a partir de experiências institucionais no âmbito de políticas públicas (GOMES, 2003) tendo por objetivo a ocupação do tempo livre da população.

Ainda na década de 1940 Sussekind (1946), enquanto dirigente do Serviço de Recreação Operária do Ministério do Trabalho, publicou estudos sistematizados sobre o lazer no Brasil. No mesmo período se percebe uma preocupação com a formação do profissional do lazer, com a inserção de disciplinas de recreação em cursos de graduação e especialização na área.

Em meados da década de 1970, foi criado em Porto Alegre o primeiro Centro de Estudo de Lazer, o CELAR/PUC. Em entrevista concedida a Werneck (2002, p.318), Andréa Bonow afirma que o grupo de estudos "ampliou o conceito de recreação para o conceito de lazer”. Até então, a recreação era focada na atividade física. A partir dos estudos realizados pelo CELAR foi possível inserir nesse contexto as manifestações artísticas e culturais. É importante destacar, também, o papel exercido pelo Serviço Social do Comércio da Regional de São Paulo (SESC-SP). Conforme apresentado por 
Bickel (2013), a entidade promoveu seminários e congressos, incluindo o I Seminário sobre o Lazer, em 1969, considerado "marco referencial para a mudança de atitude quanto à produção de conhecimentos científicos sobre o tema lazer em nosso país" (BICKEL, 2013, p.114); incentivou as discussões em âmbito nacional; adotou o lazer como foco do trabalho social institucional, ampliando sua relevância nas comunidades onde atua; criou o Centro de Estudos sobre o Lazer (CELAZER), em 1978, sob a responsabilidade de Renato Requixa, pesquisador e Diretor Regional na Administração Regional do SESC-SP; publicou diversos trabalhos de cunho científico, entre eles traduções das obras de Joffre Dumazedier, entre outras contribuições.

Desde a criação desses primeiros centros de estudos, o lazer vem se consolidando como área de conhecimento multi/interdisciplinar, porém ainda carente de pesquisas. A geração e difusão de conhecimento sistematizado são pilares fundamentais de Instituições de Ensino Superior. Programas de pós-graduação como aqueles da Universidade Federal de Minas Gerais (UFMG), Universidade Estadual de Campinas (Unicamp), Universidade Federal do Rio de Janeiro (UFRJ), Universidade Federal do Rio Grande do Sul (UFRGS), Universidade Federal do Paraná (UFPR), Universidade Metodista de Piracicaba (Unimep), entre outros, ganham relevância ao desenvolver através dos grupos de pesquisa o fortalecimento da temática do lazer, enquanto campo de estudos.

Entretanto, conforme apresentado por Peixoto (2007), apesar de existirem diversos órgãos, além das universidades, preocupados com a produção e disseminação do conhecimento, o que possibilita o reconhecimento e avanços nesta área, este conhecimento ainda é disperso, sendo difícil o levantamento do estado da arte e a identificação das problemáticas que norteiam os estudos da área no Brasil. O tema lazer 
é tratado sob diferentes perspectivas, em diversas áreas de conhecimento, sendo necessária uma sistematização que possibilite delimitações de categorias de estudo. Nesse sentido, Peixoto (2007) apresenta como resultado de sua pesquisa um banco de dados sobre o estado da arte das produções relativas ao lazer como forma de mapear o conhecimento produzido na área.

A autora promove um levantamento e catalogação das produções de lazer publicadas entre os anos de $1891^{3}$ e 2006, destacando as principais temáticas trabalhadas e sua distribuição ao longo do período. A partir desse trabalho Peixoto (2007) vem propor uma futura delimitação, de forma clara, dos marcos de categorias dos estudos de lazer. Nas palavras da autora:

\begin{abstract}
O conjunto destas dificuldades indica a necessidade urgente de análise da produção do conhecimento referente aos estudos do lazer, com vistas ao mapeamento das temáticas que vêm sendo tratadas, dos pressupostos teórico-metodológicos que vêm orientando esta vasta produção bem como da polissemia e paráfrase das categorias-chave definidoras/delimitadoras da temática típica destes estudos do lazer, com vistas à reorganização das palavras-chave que melhor identificam esta produção (PEIXOTO, 2007, p.564).
\end{abstract}

Compreende-se, assim, a relevância que os grupos de pesquisa exercem para a consolidação do conhecimento sobre determinada temática ao indicarem através das linhas de pesquisa os principais assuntos de interesse. Isto posto, interessa neste artigo fazer um mapeamento da produção de conhecimento realizada pelo grupo de pesquisa Ludicidade, Cultura e Educação - LUCE/UFMG. Os procedimentos metodológicos adotados neste artigo são apresentados a seguir.

\footnotetext{
${ }^{3}$ De acordo com a autora a publicação encontrada em 1891 é referente à recreação e trata de jogos ao ar livre e não propriamente uma obra sistematizada específica sobre lazer. Foi publicada por Alfredo Alexander com o título de Jogos ao ar livre para a mocidade brasileira.
} 


\section{Procedimentos Metodológicos}

O trabalho realizado seguiu um percurso metodológico descritivo, optando-se por uma estratégia quali-quantitativa, relacionada com o tipo de informação a ser coletada e os tipos de procedimentos a serem abordados na análise. Assim, permite-se uma percepção da realidade, possibilitando também a mensuração e o estabelecimento de relações entre os fatos examinados (SOUSA, 2016).

Para verificação das produções sobre lazer realizadas pelo grupo de pesquisa LUCE, em primeiro lugar foram levantados os participantes que teriam suas produções analisadas neste estudo, de acordo com uma consulta realizada com a líder do grupo, a pesquisadora Profa. Dra. Christianne Luce Gomes, compreendendo o período de janeiro de 2014 a agosto de 2017.

Foram consideradas produções únicas dos autores, coautoria entre participantes do grupo, bem como a participação de coautoria em trabalhos externos a ele. As produções selecionadas foram aquelas ligadas à temática do lazer. Produções distintas a esse tema, que não fizessem parte do âmbito das linhas de pesquisa do grupo, foram descartadas.

O primeiro instrumento de coleta utilizado foi um formulário criado para guiar os membros do grupo de pesquisa e padronizar as informações necessárias para a verificação das produções. O respondente deveria preencher um formulário para cada produção. Nele foram solicitadas diversas informações: nomes dos autores; área de formação do(s) autor(es) participante(s) do grupo; título da produção; palavras chave; área de conhecimento da publicação da produção; tipo de produção; ano de publicação ou previsão de término; tipo de pesquisa; técnicas de coleta de dados; participantes da 
pesquisa; e, por fim, objetivo geral e resultados para checagem do assunto relacionado ao lazer que fora trabalhado na publicação.

Os formulários foram enviados, via e-mail, para 16 pesquisadores que fizeram ou ainda fazem parte do grupo LUCE. Os formulários foram enviados em agosto/2017 para serem respondidos num prazo de 15 dias. Todos os autores retornaram as informações solicitadas.

A tabulação dos dados foi realizada com o auxílio de planilha eletrônica para posterior confecção de gráficos e análise dos resultados. As categorias tratadas na planilha foram as mesmas informadas pelo formulário.

Paralelamente, para garantir maior clareza e confiança nos dados coletados, foram visitados os currículos cadastrados na Plataforma Lattes dos 16 pesquisadores do grupo LUCE. A verificação junto ao Lattes garantiu que nenhuma produção citada no formulário estivesse sem registro no Lattes e vice-versa. Não foram verificadas inconsistências nas informações.

Importante destacar que as produções de artigos em periódicos, anais de congressos, teses e dissertações foram também pesquisadas na internet, através de busca pelo título, o que permitiu confirmar a existência dessa produção e verificar a facilidade de que, na maioria das vezes, são disponibilizadas totalmente por este meio. Os outros tipos de produção foram também checados pela internet, sendo apontados onde se encontravam publicados, porém alguns, sem disponibilidade de livre acesso. Dessa forma, todos os títulos foram buscados, tendo suas publicações comprovadas também, via pesquisa pela internet.

Em resumo, os procedimentos metodológicos utilizados para coleta de informações que geraram este estudo relativo às publicações do grupo de pesquisa 
LUCE foram: formulário, planilha de tabulação, pesquisa na Plataforma Lattes e checagem de publicações via internet.

\section{A Produção de Conhecimento e os Grupos de Pesquisa}

Desde os tempos mais remotos, o ser humano vem desenvolvendo atributos, conhecimentos e tecnologias cada vez mais complexos no intuito, entre outras possibilidades, de exercer o domínio e o controle da natureza. O conhecimento sistematizado, denominado de ciência, nasce a partir dessa necessidade de controle do meio no qual o indivíduo está inserido, possibilitando, a partir de determinados processos, a obtenção de dados que permitem a compreensão desse meio. Conforme já observava Russell (1995, p.13) “a ciência em momento algum é totalmente exata, mas raramente é inteiramente errada, e tem, como regra, mais chance de ser exata do que as teorias não-científicas. É, portanto, racional aceitá-la hipoteticamente”.

Ander-Egg (2013, p.15) apresenta a "ciência como um conjunto de conhecimentos racionais, certos ou prováveis, obtidos metodicamente, sistematizados e verificáveis, que fazem referência a objetos de uma mesma natureza". Desse modo, a relação entre ciência e conhecimento depende do exercício intelectual: o desenvolvimento de um pensamento científico capaz de extrair respostas a partir daquilo que se observa e se registra do ambiente.

Diferente do conhecimento popular, empírico, que é aprendido a partir da experiência e de modo informal, repleto de subjetividades, de acordo com o autor o conhecimento científico compreende uma sistematização de procedimentos técnicos que possibilita o ordenamento de ideias de forma racional, a construção e verificação de hipóteses daquilo que é considerado provável (ANDER-EGG, 2013). Essa visão de 
ciência é inerente às ciências tidas como tradicionais, "duras", como a física e a matemática e ainda é utilizado nas ciências sociais e humanas.

Santos (1989) reconhecia a contraposição entre a ciência e o senso comum, mas não em uma relação luz/trevas, como se os conceitos não pudessem ter pontos em comum. O conhecimento científico surgiria a partir da ruptura de conhecimentos baseados em opiniões, indo para além dele, estabelecendo meios para sua construção e constatação. Contudo, mais recentemente, o próprio autor avalia que a ciência moderna, tradicional, enfrenta uma crise que levará a um novo paradigma "de um conhecimento prudente para uma vida decente" (SANTOS, 2010, p.7). Esse paradigma se consolidaria a partir dos seguintes pressupostos: a) todo o conhecimento científico-natural é científico-social; b) todo conhecimento é local e total; c) todo conhecimento é autoconhecimento; d) todo conhecimento científico visa a se constituir em senso comum. Rechaça, assim, as distinções entre os tipos de ciência (natural ou social), bem como o preconceito ao senso comum, valorizando o ser humano.

De fato, o conhecimento científico agora está ao alcance de um clique daqueles que possuem acesso à internet, possibilitando encontrar produções de locais que dificilmente seriam procurados em outros tempos, por limitações de tempo, espaço e recursos. Conforme destaca Peixoto (2007), a disponibilização de catálogos eletrônicos de acervos de bibliotecas públicas, como a Biblioteca Nacional e bibliotecas de universidades, a existência de periódicos online e bancos de dados de áreas temáticas específicas, bem como o banco de currículo e grupos de pesquisa do Conselho Nacional de Desenvolvimento Científico e Tecnológico (CNPQ) diminuem as barreiras e ajudam a consolidar áreas de estudo. 
A autora esclarece que todo trabalho acadêmico, seja de qualquer tema ou objetivos, necessita de um levantamento do conhecimento preexistente, cuja finalidade principal é reconhecer os avanços e até mesmo as limitações presentes na produção de conhecimento de um determinado assunto. Dessa forma, é mais fácil a identificação das problemáticas que são significativas para a pesquisa e para desenvolvimento dos conhecimentos de certa área. No campo do lazer, pesquisadores se deparam com a dispersão da produção, uma vez que sendo um tema interdisciplinar, várias áreas tratarão do assunto sob diferentes perspectivas (PEIXOTO, 2007).

Nesse sentido, convém ressaltar a relevância de grupos de pesquisa como catalisadores na construção de conhecimento sistematizado. Um grupo de pesquisa caracteriza-se pela reunião de um conjunto de alunos reunidos em conjunto com um ou dois pesquisadores que possuem experiência técnica ou científica reconhecida e tem por finalidade a organização de linhas de pesquisa em torno de temas trabalhados dentro dos grupos (CNPQ, s.d.). Dessa forma, a existência desses grupos possibilita a gestão do conhecimento sobre determinado tema, reduzindo a fragmentação de informações do universo acadêmico e possibilitando avanços científicos.

Ao se buscar a página do diretório de grupos de pesquisa do sistema Lattes do CNPQ, verifica-se a quantidade de 233 grupos, vinculados a oito grandes áreas de conhecimento $^{4}$, que consideram o lazer como objeto de estudo, evidenciando o caráter interdisciplinar e a transversalidade em relação à temática. Importante pontuar que em 10 anos, desde a pesquisa realizada por Isayama e Sousa (2006), o número de grupos de pesquisa cresceu $187 \%$, passando de 81 grupos para 233, mantendo, porém, o mesmo caráter interdisciplinar.

\footnotetext{
${ }^{4}$ Pesquisa considerando o lazer como palavra no nome do grupo e/ou em linhas de pesquisa. As áreas retornadas são: Ciências Agrárias; Biológicas; da Saúde; Exatas; Humanas; Sociais Aplicadas; Engenharias e Linguística, Letras e Arte.
} 
No tocante ao grupo de pesquisa Ludicidade, Cultura e Educação (LUCE), este abrange atividades acadêmicas, culturais, sociais e pedagógicas voltadas para o estudo do lazer no Brasil e na América Latina. Vinculado ao Centro de Estudos de Lazer e Recreação da Universidade Federal de Minas Gerais (CELAR/UFMG), o grupo agrega pessoas oriundas de diversas áreas de conhecimento, que contribuem com a realização de estudos e pesquisas multi/interdisciplinares. Realiza pesquisas voltadas para o lazer em diferentes âmbitos, considerando as interfaces com diferentes temas, como processos formativos, políticas públicas, gênero e empoderamento feminino, entre outros.

Criado em 2006 sob a coordenação da professora Christianne Luce Gomes, o grupo ganhou fôlego a partir da criação do mestrado e, posteriormente, do doutorado no programa de pós-graduação em Estudos do Lazer da UFMG. Com a denominação original de LACE - Lazer, Cultura e Educação, o grupo recebeu, em 2014, a denominação LUCE, quando passou a agregar também, as atividades desenvolvidas pelo grupo de pesquisa OTIUM - Lazer, Brasil e América Latina.

Em sua descrição no Diretório dos Grupos de Pesquisa no Brasil (CNPQ, 2017), o grupo de pesquisas LUCE exibe quatro linhas de pesquisas, a saber:

\footnotetext{
i)Ludicidade, Lazer, Cultura e Educação

Descrição/objetivo: Estudar, problematizar e analisar práticas socioculturais lúdicas de lazer em múltiplos enfoques e contextos: sujeitos, conhecimentos, formação, políticas, identidades, redes de sociabilidade, diversidades de gênero, pertencimento social, geracionais, étnico-raciais, etc. Influências e ressignificações globais/locais dos lazeres nas dinâmicas sociais em suas relações com a cultura, a educação, a arte, o trabalho, a saúde, as políticas e as tecnologias, entre outros.

ii) Lazer e Ludicidade: Conhecimento, formação, política e intervenção no Brasil e América Latina

Descrição/objetivo: Estudar/problematizar o lazer e as práticas culturais lúdicas no Brasil e América Latina a partir de múltiplos
} 
enfoques, considerando relações entre agentes e contextos: sujeitos, práticas, identidades, diversidades, redes de sociabilidade, aspectos socioculturais de gênero, origem social, geracionais, étnico-raciais, de crenças, etc. Influências e ressignificações globais/locais do lazer na dinâmica cultural brasileira em suas relações com o trabalho, educação, saúde, políticas e tecnologias.

\section{iii) Lazer e Cinema}

Descrição/objetivo: Realizar estudos e pesquisas interdisciplinares sobre o lazer e as produções cinematográficas, contemplando forma/conteúdo em suas dimensões narrativas, técnicas, estéticas, sociais e pedagógicas. Análise do cinema em diferentes épocas e contextos. O turismo cinematográfico como tipologia emergente do turismo cultural. O papel das produções audiovisuais na formação do imaginário e na promoção de destinos turísticos. Limites e possibilidades do turismo induzido por filmes.

\section{iv) Geopolítica de Megaeventos Esportivos e de Lazer}

Descrição/objetivo: Esta linha objetiva pesquisar e compreender criticamente as articulações de bastidores que permeiam os megaeventos esportivos e de lazer, desvendando questões geopolíticas que afetam, sobretudo, as populações locais menos favorecidas, relações de poder, embates entre nações, estratégia política, entre outras possibilidades.

Analisar as produções voltadas aos estudos do lazer possibilita entender, principalmente, o enfoque, a periodicidade e a consistência do grupo de pesquisa. É possível levantar dados como os assuntos discutidos, os sujeitos envolvidos e metodologias utilizadas, os tipos de produção e as áreas do conhecimento. Importante destacar que por ser uma temática interdisciplinar, o lazer envolve e entrelaça diversas áreas do conhecimento. O grupo de pesquisa LUCE reflete essa situação, contando com 16 membros, de diversas áreas de formação, que contribuem com olhares e perspectivas diferentes. Como foi mencionado anteriormente, para esse estudo foram selecionadas e analisadas as produções desses membros, realizadas a partir do ano de 2014. 


\section{Resultados e Discussões}

O ponto de partida para a compreensão do papel do grupo de pesquisa LUCE para o campo dos estudos do lazer parte da própria concepção dada ao termo lazer. Nesse sentido, convém destacar a concepção de lazer elaborada pela líder do grupo, que o entende como uma necessidade humana e uma dimensão da cultura caracterizada pela vivência lúdica de manifestações culturais no tempo/espaço social (GOMES, 2014). Para a autora, a ludicidade aparece como ponto central para a compreensão do lazer, pois possibilita a satisfação da necessidade humana de diversas formas em contextos históricos, políticos e socioculturais.

Mapear os assuntos abordados bem como os pressupostos teórico-metodológicos utilizados pelo grupo de pesquisa demanda, a princípio, identificar quais contribuições foram realizadas dentro de um conjunto de temáticas propostas. Dentro dessa perspectiva, foram levantados 77 trabalhos concluídos até agosto de 2017 e 4 em andamento, com datas prováveis de finalização entre 2018 e 2020. O ápice das produções, como pode ser visualizado no Gráfico 1, ocorreu no ano de 2016 onde o número de produções mais que dobrou (131\%) em relação a 2015 e foi $43 \%$ superior em comparação a 2014. 
Gráfico 1 - Volume da Produção Anual

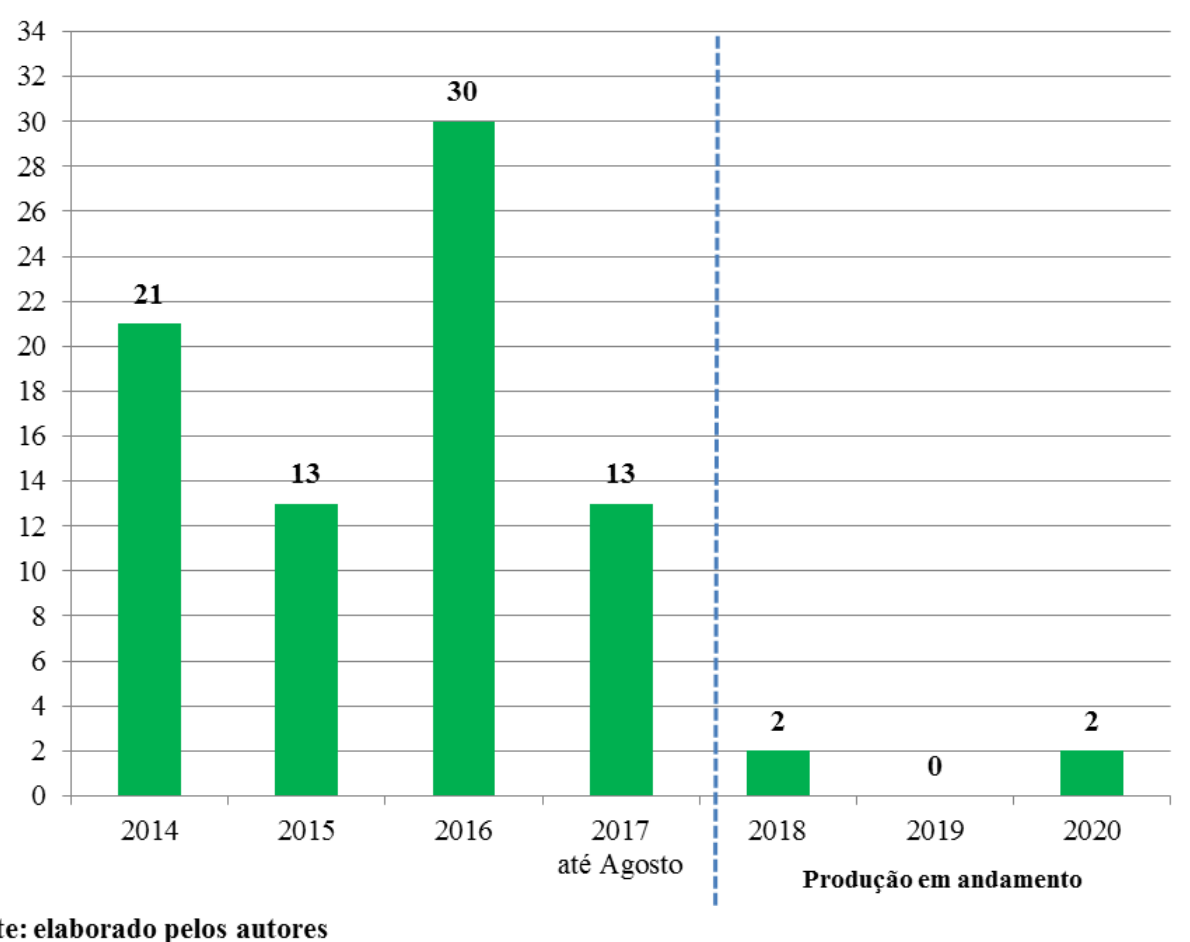

Fonte: elaborado pelos autores

Considerando os 77 trabalhos publicados até agosto de 2017, o principal tipo de produção do grupo foi a modalidade artigo científico em revistas e periódicos, com $45 \%$ do total das produções, seguido pelas publicações em anais de eventos (26\%) e capítulos de livro (14\%), conforme apresenta o Gráfico 2. As modalidades de trabalhos monográficos (tese e dissertação), livro, resenha, publicação em jornal e ensaio fotográfico também aparecem nas produções do grupo, mas não são os tipos predominantes. 


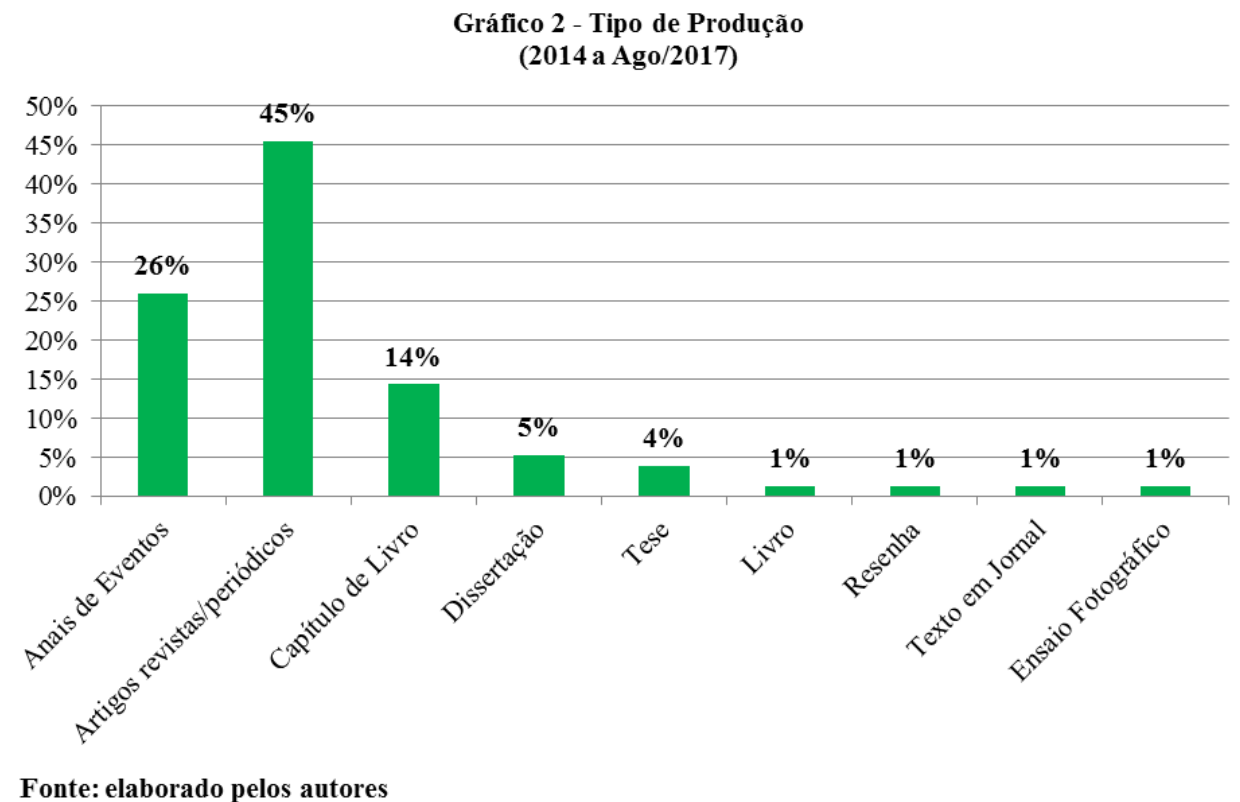

Os assuntos tratados nas produções foram levantados a partir das palavras-chave presentes nos resumos, estando contemplados no (Gráfico 3). As palavras-chave também foram utilizadas como método de verificação, em conjunto com o título da produção e seu objetivo geral, a fim de garantir que os assuntos tratados estivessem ligados ao tema lazer. O destaque fica para as produções que trabalharam o lazer com uma abordagem mais direta: vivências, atividades, espaços, direito social, tempo livre, práticas socioculturais e contextos gerais de lazer, representando $38 \%$. O turismo aparece em segundo lugar, com $30 \%$ das produções do grupo. Destaca-se que o tema megaeventos esportivos e de lazer, uma das linhas de pesquisa mais recente do grupo, aparece em 10\% das produções. Esse tipo de trabalho ganhou mais vulto, a partir da realização da Copa do Mundo de 2014 e dos Jogos Olímpicos 2016, no Brasil.

Os assuntos das publicações tratadas no âmbito do grupo LUCE estão em consonância com os assuntos presentes em outros grupos de pesquisa listados no diretório do CNPQ que tem o lazer como ponto chave em suas linhas de pesquisa. Nesses grupos, de acordo com a lista do diretório, a maioria das linhas de pesquisa 
apontam o lazer como tema principal de estudo, cerca de $40 \%$, e o turismo como ponto central de estudo em cerca de $12 \%$, sendo o segundo tema inter-relacionado e tratado pelos grupos listados. Convém salientar o papel de destaque do turismo nas discussões sobre o lazer, não só pelo LUCE, portanto, mas também em outros grupos de pesquisa, como ficou evidenciado.

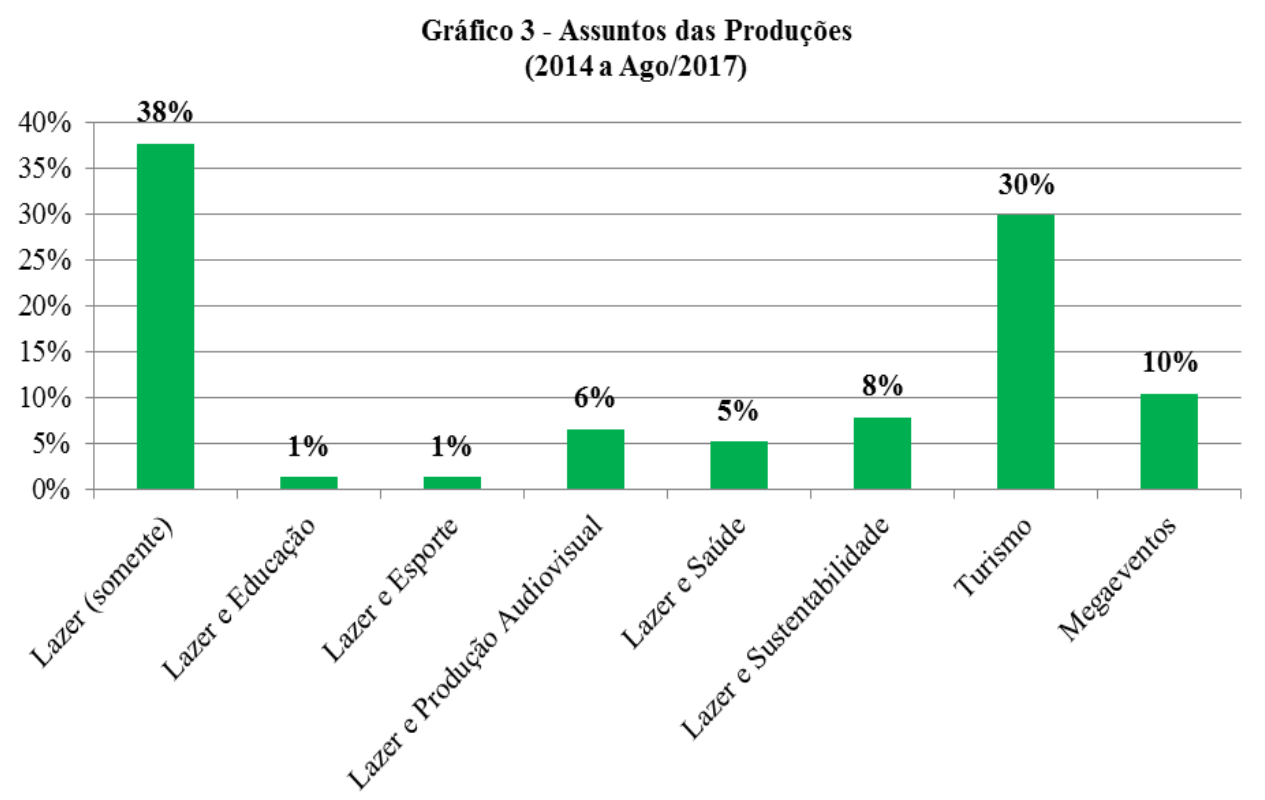

Fonte: elaborado pelos autores

Como pode ser observado no Gráfico 4, profissionais de Educação Física e Turismólogos correspondem, juntos, a quase $70 \%$ dos pesquisadores do grupo. Essa característica também se refletiu nas áreas de publicação das produções: $56 \%$ foram publicações em periódicos e/ou anais de eventos da área de lazer e $22 \%$ foram publicações nos periódicos e/ou anais de eventos relacionados à área de Turismo (Gráfico 5).

Observa-se que as áreas de publicação foram definidas a partir do título do periódico, do evento ou do trabalho monográfico. Assim, distinguiu-se, por exemplo, turismo x lazer e turismo, considerando que alguns trabalhos foram publicados em 
periódicos ou eventos que tem por foco principal o turismo de maneira geral. Em outros, o enfoque dado é para a relação do turismo com o lazer.
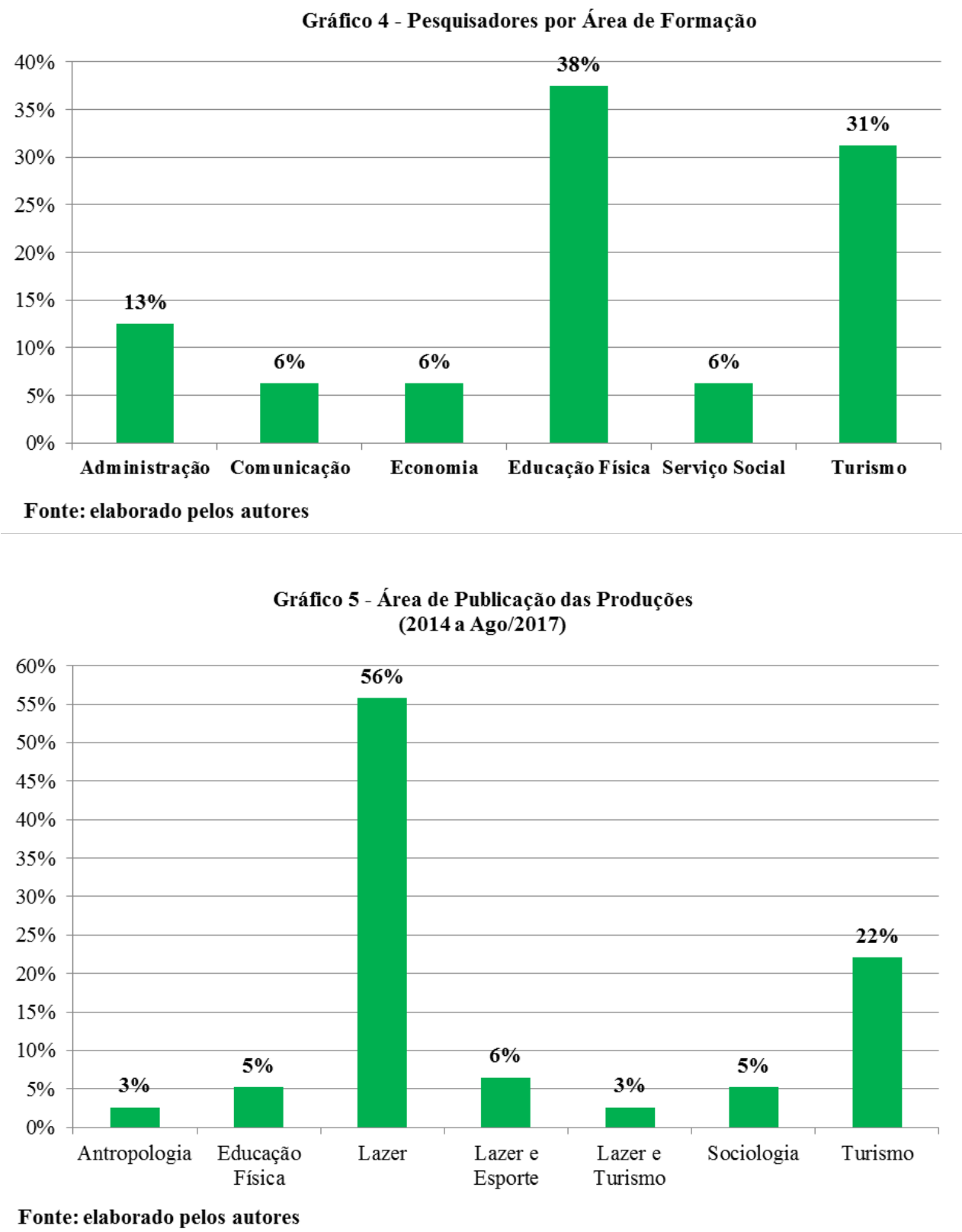

O Quadro 1 demonstra que a escolha pelos assuntos das produções tem muito a ver com a área de formação dos pesquisadores que compõem o grupo LUCE. Destaque para área de Educação Física que trata dos mais diversos assuntos relacionados à temática do lazer, e Turismólogos com $65 \%$ das publicações relativas ao assunto de sua 
área, o Turismo. Os outros pesquisadores de áreas diversas publicaram no tema ligado diretamente às questões do lazer.

Quadro 1 - Relação entre Área de Formação dos Pesquisadores e Assuntos tratados

\begin{tabular}{|l|c|c|c|c|c|}
\cline { 2 - 6 } \multicolumn{1}{c|}{} & \multicolumn{5}{c|}{ Área de Formação } \\
\hline Lazer (somente) & Adminis tração & Comunicação & $\begin{array}{c}\text { Educaçã } \\
\text { o Física }\end{array}$ & $\begin{array}{c}\text { Se rviço } \\
\text { Social }\end{array}$ & Turis mo \\
\hline Lazer e Educação & $14 \%$ & $7 \%$ & $72 \%$ & $3 \%$ & $3 \%$ \\
\hline Lazer e Esporte & & & $100 \%$ & & \\
\hline Lazer e Produção Audiovis ual & & & $100 \%$ & & \\
\hline Lazer e Saúde & & & $100 \%$ & & \\
\hline Lazer e Sustentabilidade & & & $100 \%$ & & \\
\hline Turis mo & & & $100 \%$ & & \\
\hline Megaeventos & & & $35 \%$ & & $65 \%$ \\
\hline
\end{tabular}

Fonte: elaborado pelos autores

O Gráfico 6 apresenta aspectos metodológicos no que se refere ao tipo de pesquisa utilizado nas produções do grupo. Destaca-se que as pesquisas realizadas no âmbito do grupo LUCE são predominantemente qualitativas e empíricas, atingindo um percentual de $77 \%$ das publicações. Estas pesquisas tiveram como principais instrumentos de coleta de dados, além do levantamento bibliográfico, as entrevistas. Contudo, diversas técnicas como a observação, survey, análise fílmica, entre outras, também foram utilizadas, conforme apresenta o Gráfico 7. 


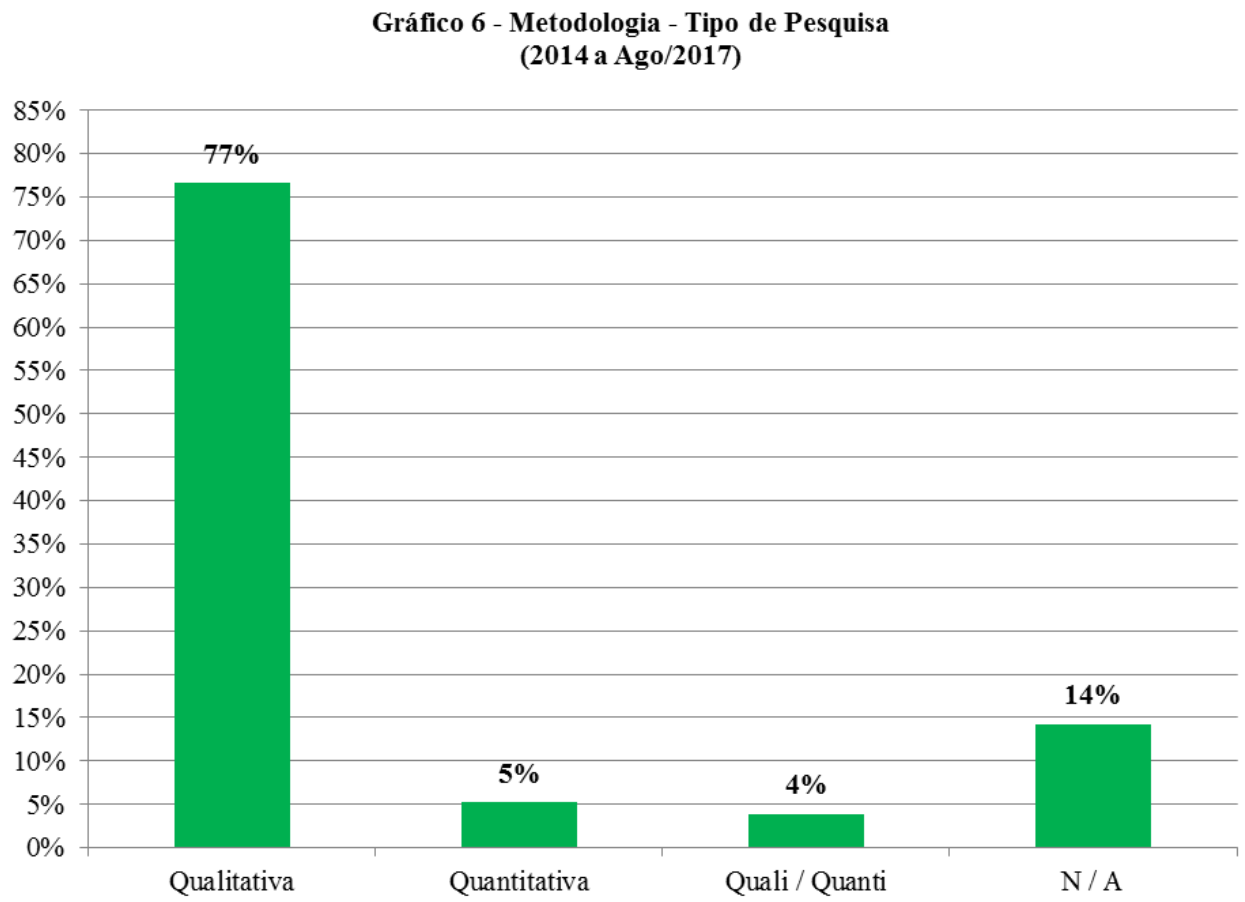

Fonte: elaborado pelos autores

Gráfico 7 - Metodologia - Instrumentos de Coleta de dados utilizados para as Produções *

(2014 a Ago/2017)

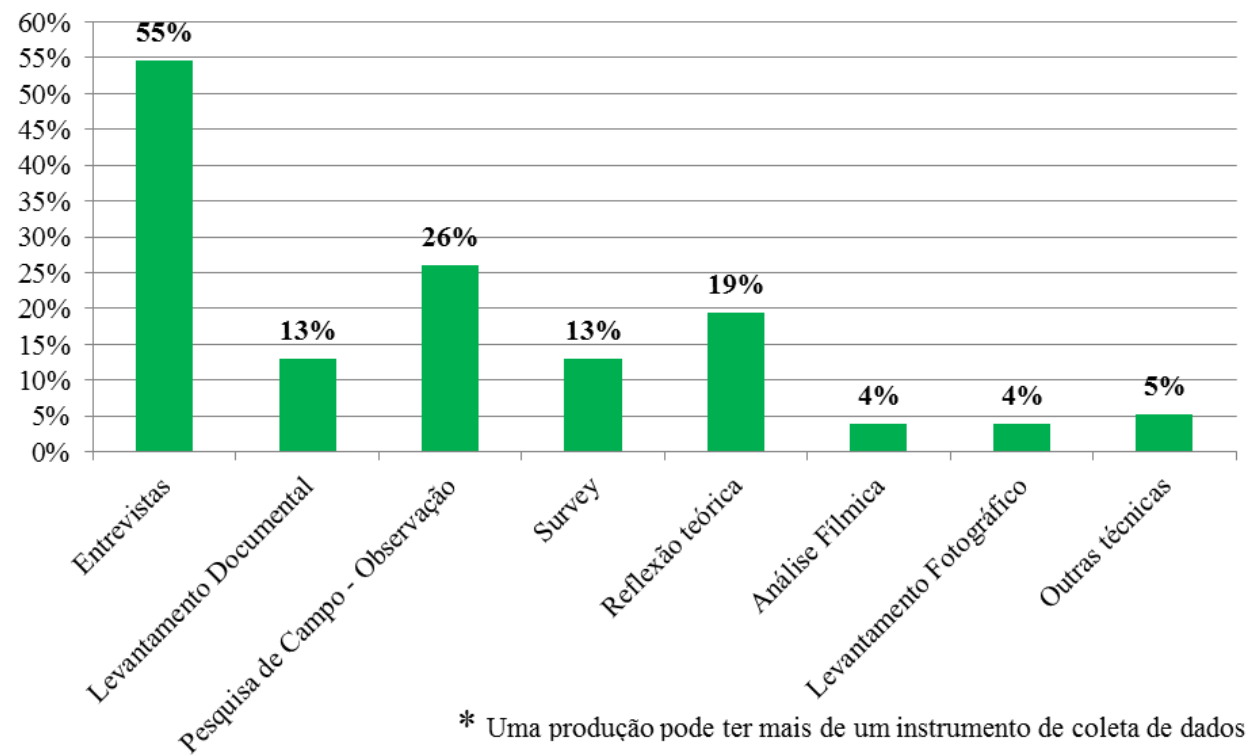

Fonte: elaborado pelos autores

Tratando-se das metodologias empregadas nas pesquisas do grupo, a contribuição do LUCE para o campo do lazer se destaca na diversidade de abordagens de estratégias e instrumentos de coleta. Apesar de grande parte das pesquisas utilizarem 
a estratégia qualitativa, baseada principalmente em coleta de informação por meio de entrevistas, a reflexão teórica e a observação tomam, também, uma boa parcela das produções. Observa-se ainda, a presença de estratégias quantitativas e quali/quanti fazendo parte das produções do grupo. Portanto, o grupo traz para o campo do lazer aspectos metodológicos diversos que podem ser utilizados como referencial para outras produções, tanto do próprio grupo, como para outros pesquisadores que queiram estudar sobre os temas relacionados ao lazer.

Em relação aos principais sujeitos considerados nas pesquisas, onde a análise é aplicável, verifica-se que $16 \%$ das amostras foram compostas por estudantes e outros $16 \%$ foram compostas por gestores e organizadores (setores público, privado e não governamentais). Em $13 \%$ dos trabalhos o foco foi dado a professores e diretores de escolas e em $12 \%$ o objetivo foi pesquisar os residentes dos locais onde as pesquisas eram realizadas. O Gráfico 8 apresenta esses resultados. Uma tendência maior para escolha dos sujeitos de pesquisa pode ser verificada em relação a estudantes e gestores, o que sugere a formação e o desenvolvimento do lazer como foco desses estudos. 


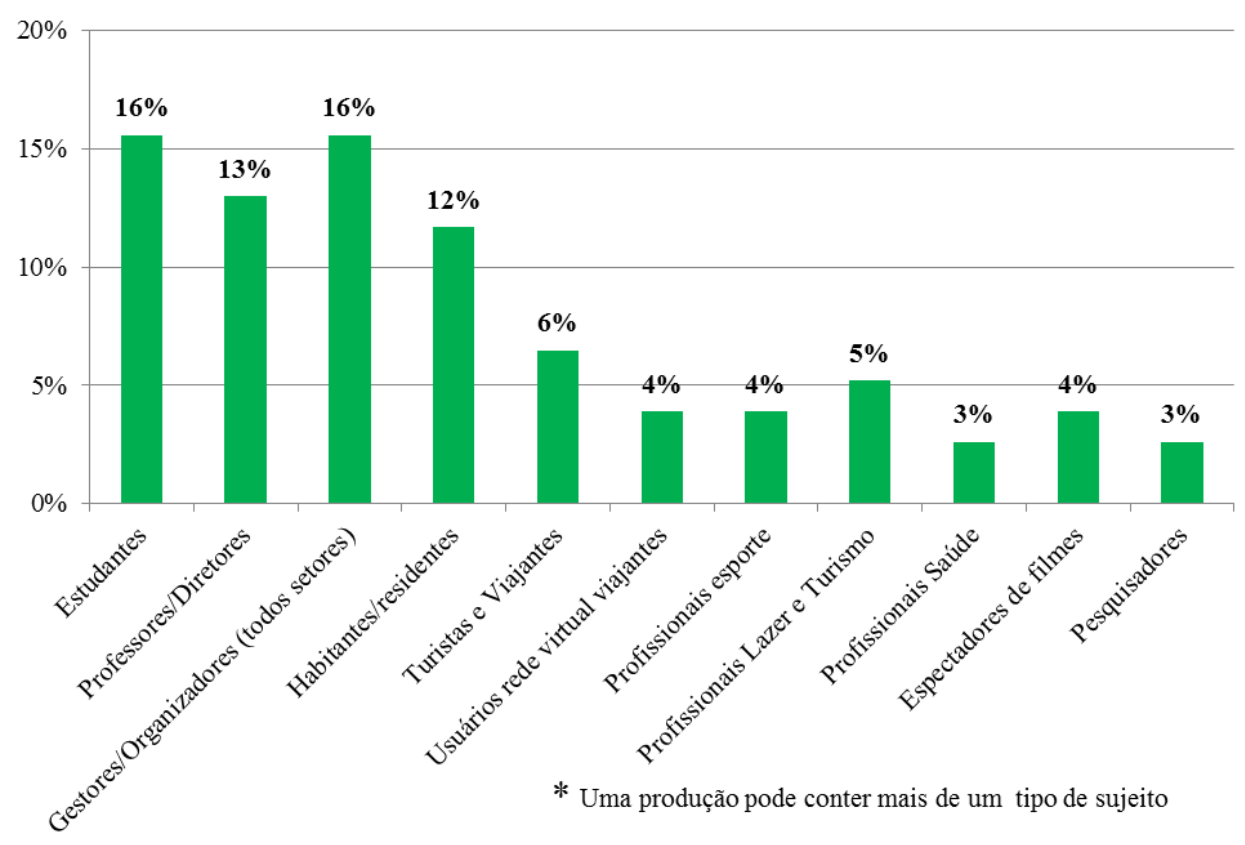

Fonte: elaborado pelos autores

Ressalta-se a diversidade em relação aos tipos de sujeito trabalhados nas investigações. Uma pesquisa do campo do lazer pode levar em conta diferentes e variados sujeitos, já que é uma área interdisciplinar e as produções aqui demonstram essa variedade. Destaque para os sujeitos ligados à formação e desenvolvimento, como também as populações locais, turistas e profissionais que trabalham na promoção do lazer.

Os temas trabalhados nas produções do grupo LUCE vão desde o cinema, os eventos esportivos, a cultura, educação, esporte e o turismo, ou seja, práticas culturais lúdicas, vivenciadas como lazer. Esses estudos verificaram as relações entre as interfaces do lazer, construído a partir de três elementos inter-relacionados: o tempo/espaço social, as manifestações culturais e a ludicidade. O lazer nas produções do LUCE é considerado numa perspectiva "contra-hegemônica", o que possibilita a construção de novos conceitos e discussões para o campo do lazer. Trata da significação de um lazer que consiga abarcar, assim, novos contextos e possibilidades de 
compreensão, como por exemplo, as produções do grupo que tratam do lazer das minorias tais como, comunidades tradicionais, indígenas, quilombolas, ribeirinhos, etc., e em consonância com as ideias apontadas por Gomes $(2004,2014)$.

Observa-se que a multiplicidade de assuntos relacionados ao tema lazer contemplada nas linhas de pesquisa do LUCE evidencia as principais contribuições ao campo, de acordo com as investigações realizadas pelo grupo: lazer e diversidade cultural; lazer, cinema latino-americano e empoderamento feminino; questões sobre a oferta cultural pública e a indústria cultural; indústrias culturais e criativas; direito ao lazer no Brasil e nos países andinos; formação de agentes sociais nas políticas públicas de lazer; tempo livre e recreação na sociedade latino-americana; lazer em rios urbanos na tríplice fronteira; lazer nas empresas; relações lazer/trabalho frente às problemáticas ambientais e ecoturismo na América latina; o turismo all inclusive; desenvolvimento regional do turismo e lazer; interfaces entre lazer e turismo na produção de conhecimento; lazer e turismo via rede de viajantes; hospitalidade; turismo comunitário; abordagens do brincar; vivências de lazer em hospitais; prática social de músicos de rua; a prática dos mochileiros; megaeventos esportivos e seus impactos sociais.

Nesse sentido, o grupo de pesquisa LUCE pode contribuir na formação do campo interdisciplinar dos estudos do lazer ao envolver diversas linhas de pesquisa e tratar de abordagens variadas que vão se entrelaçar ao tema, retratando e discutindo experiências de lazer no Brasil e América Latina, de forma sistematizada.

\section{Considerações Finais}

Identificar o estado da produção do conhecimento de determinado campo de estudos permite o planejamento de trabalhos futuros, abordando aspectos ainda pouco 
explorados. A ampliação e a consolidação dos conhecimentos dentro dos estudos do lazer tornam-se necessárias para garantir o direito aos cidadãos, apesar de todas as complexidades do mundo contemporâneo.

Como foi tratado neste artigo, o grupo de pesquisa LUCE propõe problematizar e analisar as práticas socioculturais lúdicas de lazer sob diferentes perspectivas e contextos, no Brasil e na América Latina. As produções analisadas retratam os objetivos presentes nas linhas de pesquisa seguidas. Nesse sentido, o grupo colabora na sistematização de conhecimentos, auxiliando na construção do saber no campo do lazer. Possibilita, também, uma difusão dos estudos culturais para a região geopolítica estudada.

O grupo de pesquisa LUCE assume a ludicidade como conceito que demarca a compreensão do fenômeno lazer. Enquanto muitos pesquisadores compreendem o lazer como contraponto do trabalho, e tendem a abordar o lazer a partir desse viés, no grupo o foco está diretamente relacionado com a ludicidade; com as práticas culturais lúdicas vivenciadas pelas pessoas. Dessa maneira, o lazer deixa de ser um mero apêndice do trabalho produtivo, para ganhar visibilidade e relevância por si mesmo.

Entre os limites deste mapeamento, destaca-se a adoção de um recorte temporal que não reflete a totalidade de estudos já realizados pelo grupo. Apesar disso, acreditase que a adoção do quadriênio foi capaz de traduzir o contexto atual de produções do grupo LUCE. Isso sugere, inclusive, o nascimento de novos caminhos de pesquisa, como é o caso das linhas "Lazer e Cinema" e "Geopolítica de Megaeventos Esportivos e de Lazer", que vem ganhando destaque dentro do grupo e indica novas tendências de pesquisa para o futuro. 


\section{REFERÊNCIAS}

ADORNO, T. W.; HORKHEIMER, M. Dialética do esclarecimento: fragmentos filosóficos. Rio de Janeiro: Jorge Zahar, 1985.

ANDER-EGG, E. Técnicas de investigación social. Editora Lumen, 2013.

BICKEL, M. C. P. O Serviço Social do Comércio e a produção de conhecimentos sobre o lazer no Brasil: década de 1970. 2013. Dissertação (Mestrado) UFMG/EEFFTO, Belo Horizonte, 2013.

CNPQ. Diretórios dos grupos de pesquisa no Brasil. Lattes. Disponível em: $\mathrm{http} / / /$ lattes.cnpq.br/web/dgp/faq?p_p_id=54_INSTANCE_39Zlb9kA3d0e\&p_p_lifecyc le $=0 \& p \_p \_s t a t e=$ normal $\& p \_p \_$mode $=$view\&p_p_col_id $=$column-

3\&p_p_col_count $=1 \& \_54 \_I N S T A N C E \_39 \mathrm{Zlb} 9 \mathrm{kA} 3 \mathrm{~d} 0 \mathrm{e}$ struts_action $=\% 2 \mathrm{Fwiki}$ displa $\mathrm{y} \% 2 \mathrm{Fview} \dot{\&}$ 54_INSTANCE_39Zlb9kA3d0e_nodeName=Main\&_54_INSTANCE_39 Zlb9kA3d0e title $=\mathrm{G} 01 .+\mathrm{O}+$ que $+\% \mathrm{C} 3 \% \mathrm{~A} 9 \% 20 \mathrm{um}+$ grupo $+\mathrm{de}+$ pesquisa $\% 3 \mathrm{~F}+\mathrm{Como}+\mathrm{sa}$ ber + se + as + atividades + desenvolvidas + por + um + conjunto + de + pesquisadores + constituem +um+grupo+de+pesquisa\%3F . Acesso em 02 jun. 2017.

CNPQ. Diretórios dos grupos de pesquisa no Brasil. Lattes. Grupo de pesquisa LUCE - Ludicidade, Cultura e Educação. Disponível em: http://dgp.cnpq.br/dgp/espelhogrupo/1712454786501131 . Acesso em 13 jun. 2017.

DUMAZEDIER, Joffre. Sociologia empírica do lazer. São Paulo: Perspectiva, 1973.

FERREIRA, A. Lazer operário: um estudo de organização social das cidades. Salvador: Livraria Progresso, 1959.

GOMES, C. L. Significados de recreação e lazer no Brasil: reflexões a partir da análise de experiências institucionais (1926 - 1964). 2003. Tese (Doutorado) UFMG/FAE, Belo Horizonte 2003.

Dicionário Crítico do lazer. Belo Horizonte: Editora Autêntica, 2004.

. Estudos do lazer e geopolítica do conhecimento. Licere. Belo Horizonte, v. 14, 2011.

. Lazer como necessidade humana e dimensão da cultura. Revista Brasileira de Estudos do Lazer. Belo Horizonte, v. 1, n.1, p. 3-20, 2014.

ISAYAMA, H.F; SOUSA, A.P.T. Lazer e educação física: análise dos grupos de pesquisa em lazer cadastrados na plataforma LATTES do CNPQ. Buenos Aires, Revista Digital, Ano 11, nº 99, 2006.

LAFARGUE, P. O direito à preguiça. São Paulo: Hucitec, 1999.

LEFEBVRE, H. O direito à cidade. São Paulo: Moraes, 1991. 
MARCELLINO, N. C. Contribuições de autores clássicos modernos e contemporâneos para os estudos do lazer. Licere, Belo Horizonte, v.13, n.4, dez/2010.

MEDEIROS, E. B. O lazer no planejamento urbano. Rio de Janeiro: Fundação Getúlio Vargas, 1971.

PEIXOTO, E. Levantamento do estado da arte nos estudos do lazer: (Brasil) Séculos XX e XXI - alguns apontamentos. Educ. Soc., Campinas, v.28, n. 99, p. 561-586, maio/ago. 2007. Disponível em: http://www.scielo.br/pdf/es/v28n99/a14v2899.pd . Acesso em: 22 Jun 2017.

RIESMAN, D. A multidão solitária. São Paulo: Perspectiva, 1975.

RUSSEL, B. My philosophical development. 2. ed. London: Routledge, 1995.

SANTOS, B. S. Introdução a uma ciência pós-moderna. Rio de Janeiro: Graal, 1989.

. Um discurso sobre as ciências. 16. ed. Porto: B. Sousa Santos e Edições Afrontamento, 2010. 59p.

SOUSA, P. R. Manual para Concepção e Desenvolvimento de Projetos Aplicativos: Metodologia. Belo Horizonte: FDC, 2016.

SUSSEKIND, Arnaldo. Trabalho e Recreação. Rio de Janeiro: Ministério do Trabalho, Indústria e Comércio, 1946.

WERNECK, Christianne L.G. Trajetória do primeiro Centro de Estudos de Lazer no Brasil (1973-1978): Conversando com Andréa Bonow. Licere. Belo Horizonte, v. 5. n. 1, p. 127-133, 2002.

\section{Endereço dos Autores:}

Juliara Lopes da Fonseca

Escola de Educação Física, Fisioterapia e Terapia Ocupacional

Universidade Federal de Minas Gerais (EEFFTO/UFMG)

Av. Antônio Carlos, 6627 Pampulha

Belo Horizonte - MG - 31.270-901

Endereço eletrônico: juliarafonseca@gmail.com

Eduardo Penna de Sá

Escola de Educação Física, Fisioterapia e Terapia Ocupacional Universidade Federal de Minas Gerais (EEFFTO/UFMG)

Av. Antônio Carlos, 6627 Pampulha

Belo Horizonte - MG - 31.270-901

Endereço eletrônico: epenna@hotmail.com 